\title{
SMC BASED GRID INTEGRATED SOLAR PV SYSTEM USING SUPERLIFT BOOST CONVERTER
}

\author{
P.Pugazhendiran ${ }^{\# 1,}$ Mohamed Imran.R ${ }^{\# 2}$, Anwar Batcha.J.J ${ }^{\# 3}$ \\ \# 1, Professor, ${ }^{2,3}$ UG Scholars \\ \# 1,2,3 Department of Electrical and Electronics Engineering, \\ IFET College Of Engineering, Villupuram, Tamil Nadu,India \\ pugazhifet@gmail.com ${ }^{1}$,rafikimran96@gmail.com ${ }^{2}$ jafarbatcha786@gmail.com ${ }^{3}$
}

\begin{abstract}
Due to the insufficient non-renewable resources, industrial growth and technological development in India, there is an energy scarcity in now a days. So it is necessary to overcome and to produce power from the renewable energy resources. The solar power production technique plays a vital role in the modern world. This paper presents a conversion of renewable energy source into electrical power and integrated with an existing grid, which is having same voltage and frequency. The major concentrations in this work is to focus the Super Lift Boost Converter (SLBC), which is used to step up the voltage and current into higher level and a grid tracking inverter which is used to track the grid voltage. The incremental conductance method is used to extract the maximum power from the PV Cells to achieve maximum efficiency. This work is aimed to assess an incremental conductance method to extract the maximum power from solar cells and integrated with live grid with low cost and high reliability.
\end{abstract}

Keyword-Super lift boost converter, MPPT, PV Cell,Incremental conductance,Grid Integration,SMC

\section{INTRODUCTION}

The main objective of this work is to feed the generated power from the solar panels to the grid by using the grid tracking inverter. Most of the power generation is carried out by non-renewable resources such as coal and fossil fuel based power plant which contribute heavily to greenhouse gas emission and highly pollute the environment. But in case of solar power plant which is the renewable resources, and does not produce any environmental effects and it is zero or low carbon electric power generation. The solar power production is most widely used renewable power system. The electricity generated by a grid connected PV system will reduce the power bill and we can supply the surplus amount of electricity to the local electricity supplier. This work uses the MPPT technique which is used to extract the maximum power from the PV panels. The MPPT is the process of finding the maximum power point and keeping the load characteristics there. This paper uses the Super lift Boost converter which is used to boost the input voltage to the higher level at different stages without any parasitic effect. It also increases the efficiency and reliability. The super lift boost converter is implemented by using the diodes and capacitors at each stage. Then the power is stored in the battery bank and then it is supplied to the grid tracking inverter from this inverter, the power is given to the load and the remaining power is fed to the grid based on the synchronization. It is mostly used because they maintenance free and also pollution free.

The power produced from the solar panels will be low voltage, direct current (DC) and cannot be applied to AC machines. The objectives of this proposal are to develop a system that converts the power from the solar panel to the supply having the same voltage, same frequency with respect to the traditional power plant.

Despite all the advantages presented by the generation of energy through the use of PV cells, but the efficiency of the energy conversion is currently low and the initial cost implementation is still high, so it is necessary to extract the maximum power from the panel to achieve the maximum efficiency in the operation. To extract the maximum power the MPPT technique is used. This paper also aims to asses an improved incremental conduction method to extract the maximum power. 


\subsection{Block diagram:}

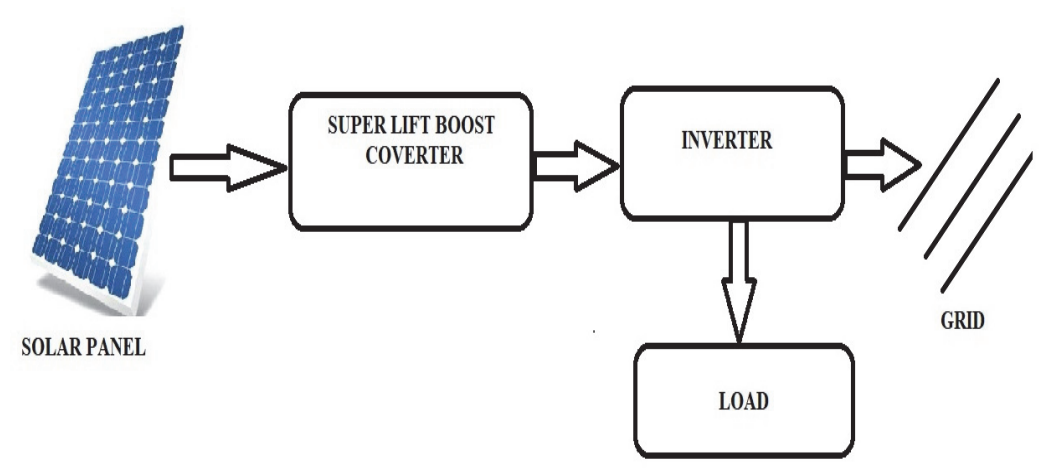

Fig. 1.Block diagram

The solar panel produces DC voltage when the sunlight falls on it. The Converter will make the produced by the solar panel to constant DC current by super lift boost converter. Produced power is converted to $230 \mathrm{v} / 50 \mathrm{~Hz}$ and synchronized with the grid's supply with the help of grid tracking inverters.

The organisation of this paper is as follows. The block diagram of the entire grid integrated system with its components is explained in section1.The PV cells and MPPT technique is described in section2. The super lift boost converter for grid integration is focused in section3.In section 4; the controller(sliding mode) are explained. The results and discussion of this work arepresented in section5. The conclusion of this work is described in section6.

\section{SOLAR CELL AND MPPT}

The photovoltaic cell or photoelectric cell is a semiconducting converter, which converts the light energy into electrical energy based on the irradiance fall on the PV panel throughout the day. If the sun rays fall on the panel is higher, it results the more current. The current flow in the

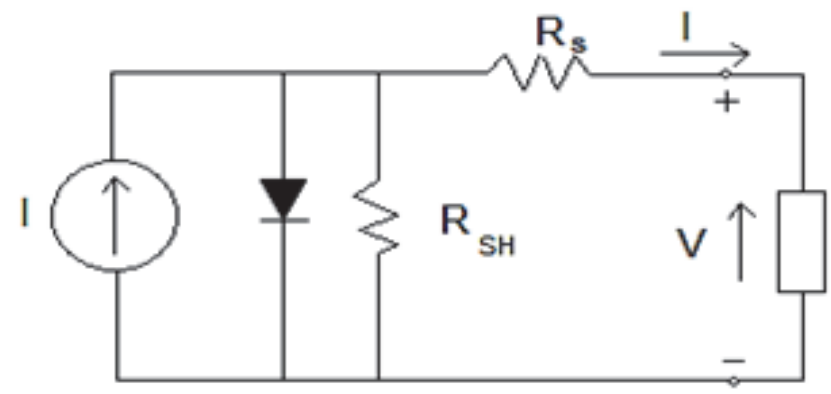

Fig. 2.Equivalent circuit for solar cell

Panel with diode is $I, R_{s}$ is the series resistance and $R_{s h}$ is the shunt resistance. The solar

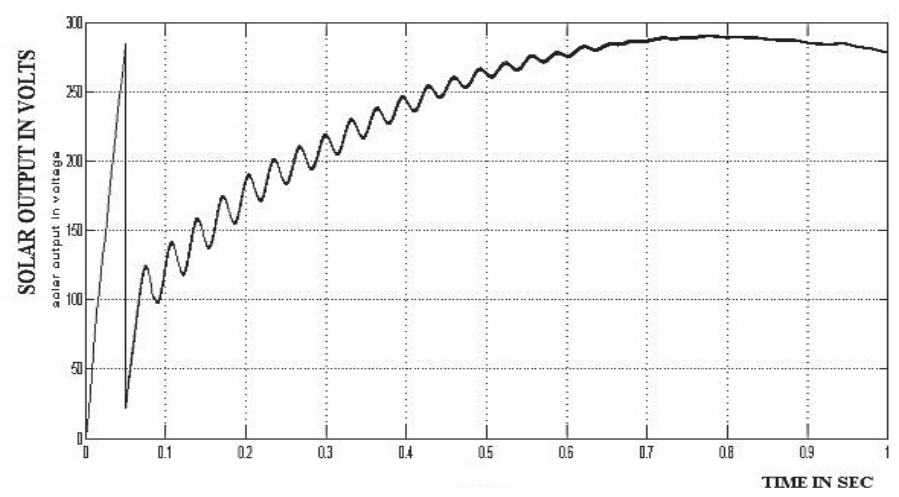

Fig.3.Solar panel output voltage 
panel produces $300 \mathrm{v}$ and it is shown in fig 3 . The output equation of solar panel is

$$
\begin{array}{r}
I=I_{S C}-I_{d} \\
I_{d}=I_{0}\left(e^{q V d / k t}-1\right)
\end{array}
$$

Where $I_{0}$ is the reverse saturation current of diode, $q$ is the electron charge, $V_{d}$ is the voltage across the diode is the Boltzmann constant $\left(1.38 * 10^{-19} \mathrm{~J} / \mathrm{K}\right), \mathrm{T}$ is the temperature in kelvin( $\left.\mathrm{K}\right)$

$$
\begin{gathered}
I=I_{s c}-I_{0}\left(e^{q\left(\frac{v+I R s}{n k t}\right)}\right) \\
I=I_{s c}-I_{0}\left(e^{q V d / k t}-1\right)
\end{gathered}
$$

Where ,I is the photovoltaic current, $\mathrm{V}$ is the voltage and $\mathrm{T}$ is the temperature . The Solar panel output voltage current characteristics is shown in fig 4.

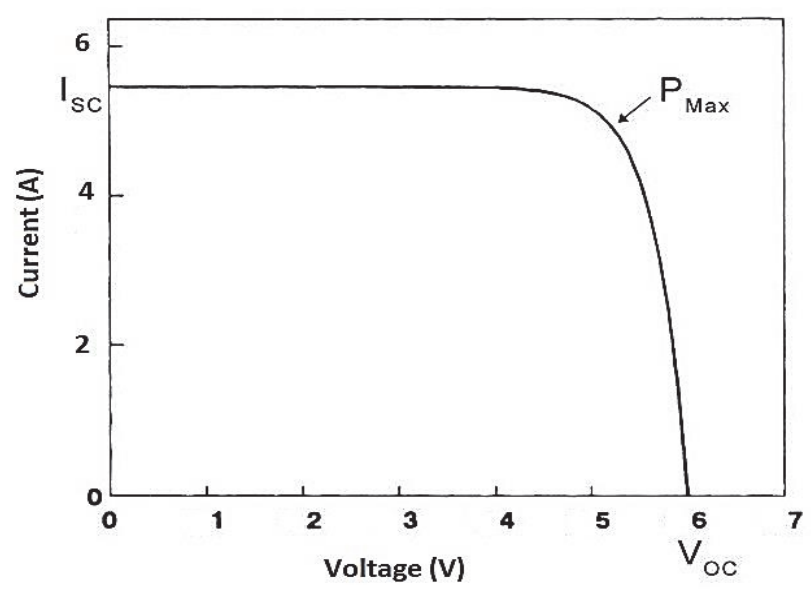

Fig.4. VI Characteristics of solar panel

\subsection{MPPT Technique}

The Maximum Power Point Tracking (MPPT) technique is used to obtain maximum power from the solar and also to attain maximum efficiency. In this, paper the Incremental Conductance method is used because it overcomes the disadvantages of perturbs and observes $(\mathrm{P} \& \mathrm{O})$ method. TheIncremental conductance method determines that MPPT has reached a maximum power point and stop the perturb. This algorithm has advantages over $\mathrm{P} \& \mathrm{O}$ and the maximum power point is easily determined than $\mathrm{P} \& \mathrm{O}$. Also, incremental conductance can track rapidly increasing and decreasing irradiance conditions with higher accuracy than P\& O. In this method the peak power of the module lies at above $98 \%$ of its incremental conductance.

$$
\begin{aligned}
& (d p / d v)_{M P P}=d(V I) / \mathrm{dv} \\
& 0=I+V d i / d v_{M P P} \\
& \frac{d I}{d v_{M P P}}=-\frac{I}{V}
\end{aligned}
$$

The above equations are the equations incremental conductance 


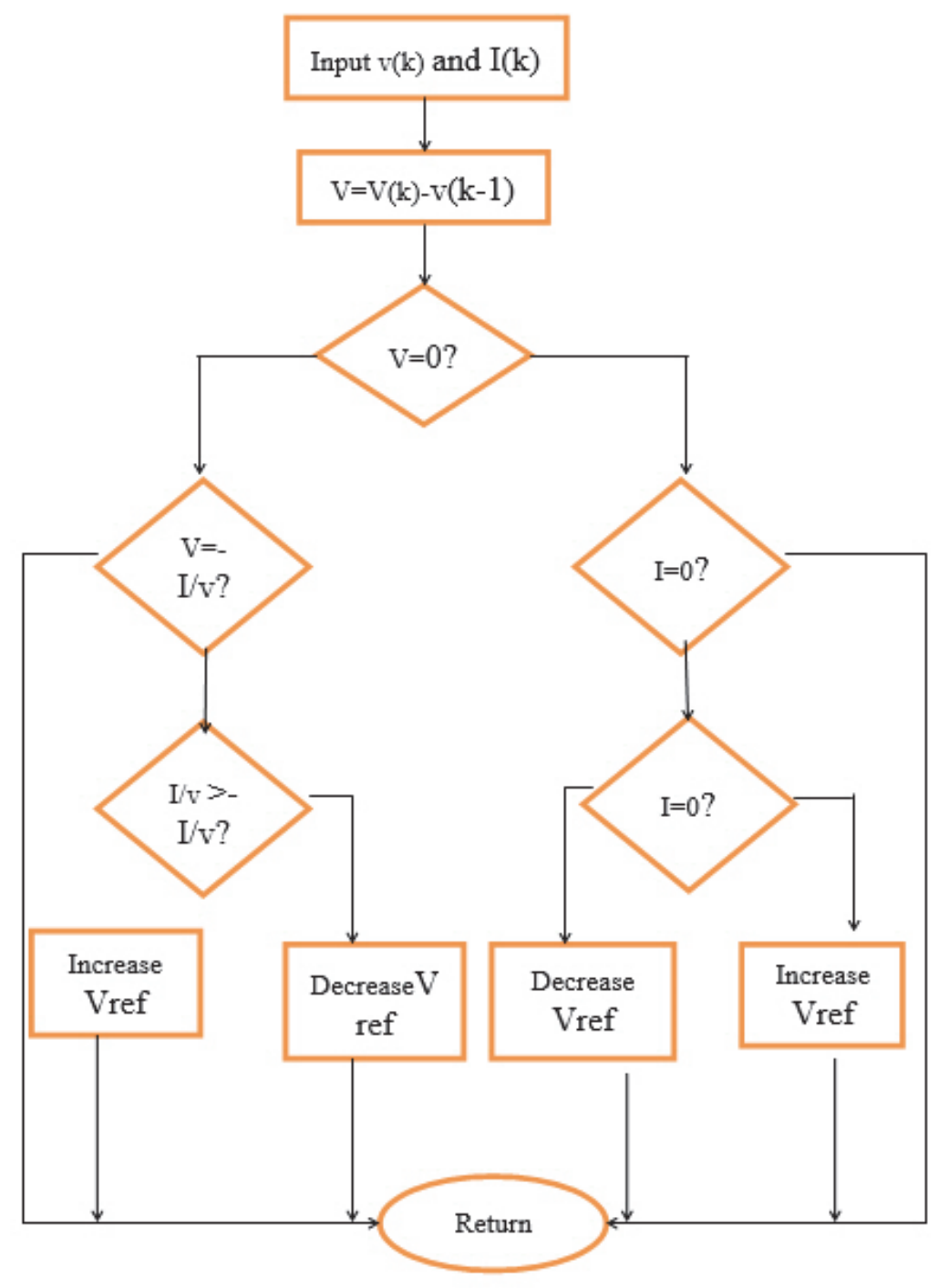

Fig 5. Flow chart of incremental conductance MPPT

The Fig.5is the Flowchart of incremental conductance MPPT.The fig.6 shows the simulation of the incremental conductance method. The output from the MPPT controller is given as the gate pulse to the MOSFET in the converter circuit. The incremental conductance method has more efficient than the other MPPT controllers. It tracks the maximum amount of output from the solar panel.

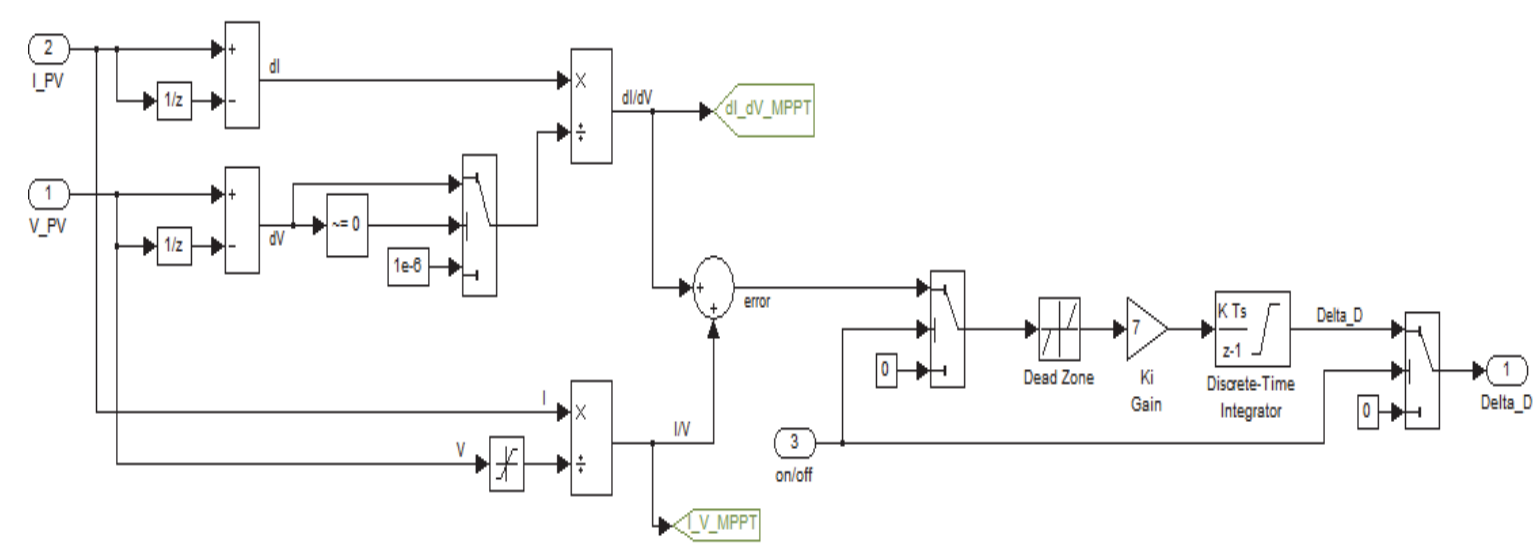

Fig.6.Simulation for incremental conductance 


\section{SUPER LIFT BOOST CONVERTER}

The super lift boost converter is used to regulate the produced DC powerfrom the PV panel and boost the produced power up to 4 times without parasitic effect, thereby increasing efficiency and reliability. The Superlift converter works in current fed full bridge transformer topology to increase the voltage transfer gain. It effectively enhances the voltage transfer gain in power series. Super lift boost converter lifts the voltage stage by stage in geometric progession.

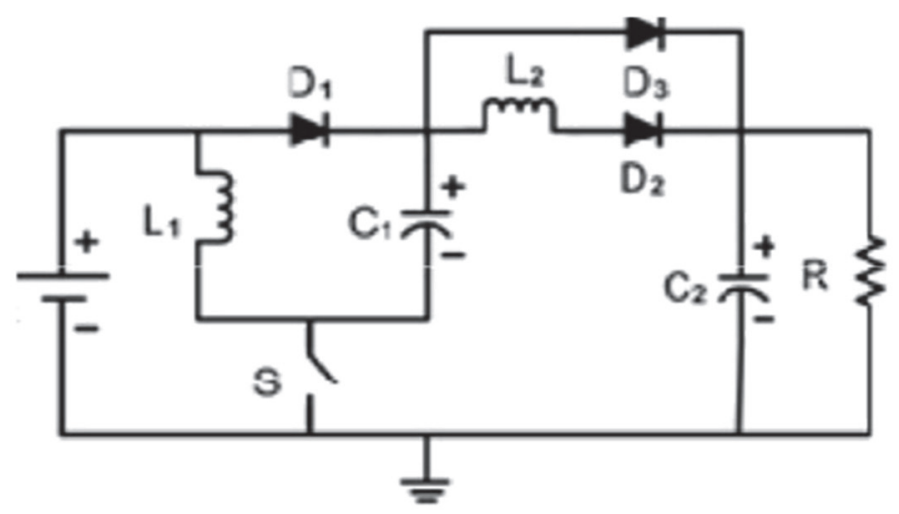

Fig.7.Super liftBoost Converter

From the above Fig.7,

$$
V_{0}=\left[\frac{2-k}{1-k}\right]
$$

Where $\mathrm{k}$ is the duty cycle

The output equation is given by

$$
V_{0}=\left[\frac{2-k}{1-k}\right]^{2}
$$

It works in two modes .In Mode 1 Switch is in ON position and under Mode 2 Operation switch is in OFF position. The detailed operation with direction of current flow is shown in fig.8 and Fig.9.

MODE 1:
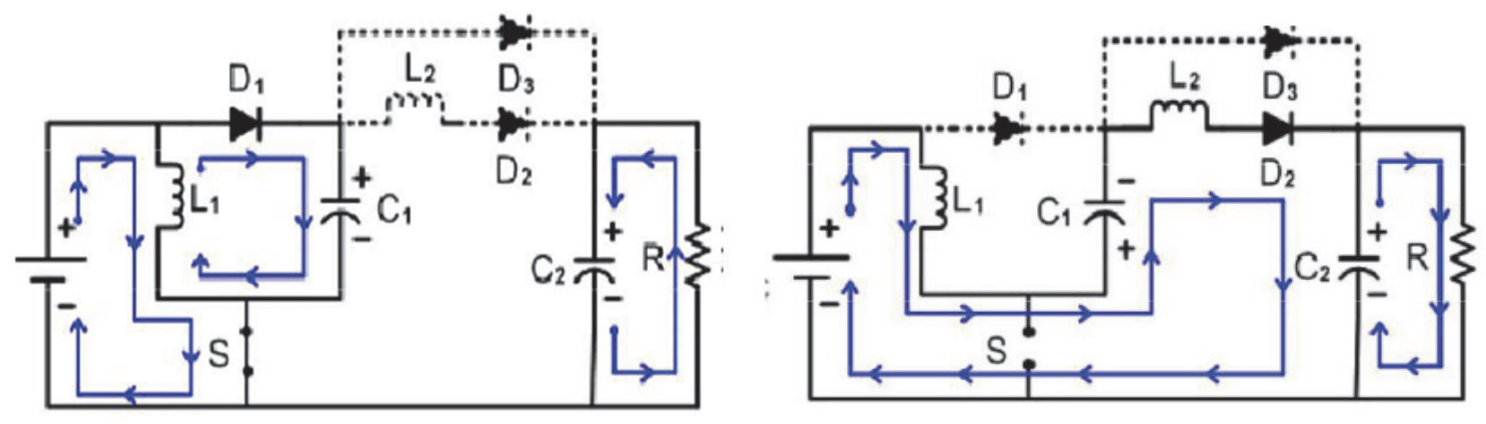

Fig.8 Mode1 operation of SLBCFig.9 Mode2 operation of the SLBC

The fig. 8 shows the operation of mode I, here the switch is under ON condition. The current flows through the inductor $L_{1}$ and capacitor $C_{1}$ and energy is stored in capacitor $C_{2}$. The fig. 9 shows the operation of mode 2 . Here the switch is under the OFF condition. The stored energy in inductor $\mathrm{L}_{1}$ and capacitor $\mathrm{C}_{1}$ gets discharged across $\mathrm{L}_{2}$ and $\mathrm{C}_{2}$,which boost the output voltage. The super lift boost converter is used because there is no parasitic effect.The fig 10 and Fig 11 are the input and output voltage waveforms of SLBC. 

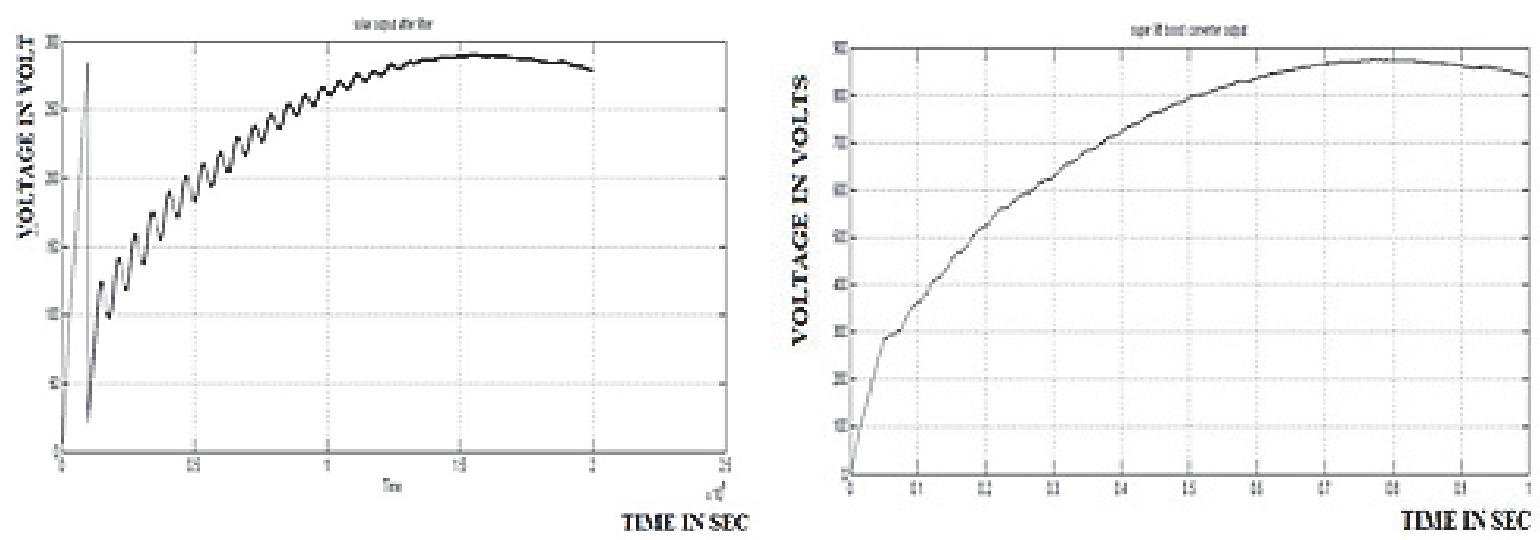

Fig. 10 input waveform of SLBCFig. 11 output waveform of SLBC

\section{CONTROLLER}

The controller adopted in this work is sliding mode controller, which controls the circuit by constant frequency. The steady state error elimination is necessary because it uses constant frequency operation.Sliding-mode control of variable structure systems, such as power converters, is particular interesting because of the inherent robustness, capability of system order reduction, and appropriateness to the on-off switching of power semiconductors.All the designed controllers for power converters are in fact variable structure controllers, in the sense that the control action changes rapidly from one to another of, usually, two possible $\mathrm{d}$ values, cyclically changing the converter topology. The Fig.12 is the Simulink model of the Sliding Mode controller (SMC)

The steady state error elimination is necessary because it uses constant frequency operation.Bythe Control law theSlidingSurface is,

$$
\begin{gathered}
d x_{j} / d t=\sum_{i=h}^{j-1}(k i / k h) \\
d x_{j} / d t=\sum_{i=g}^{j-1} d x_{i} / k_{j} d t
\end{gathered}
$$

Where $\mathrm{k}, \mathrm{j}$ are independent variable of the system and $\mathrm{x}$ is the system

By Switching Law

$$
u_{h}(t)=\left\{\begin{array}{c}
U / b_{e}(e), s\left(e_{x i}, t\right)>+\ni \\
-U / b_{e}(e), s\left(e_{x i}, t\right)<-\ni
\end{array}\right\}
$$

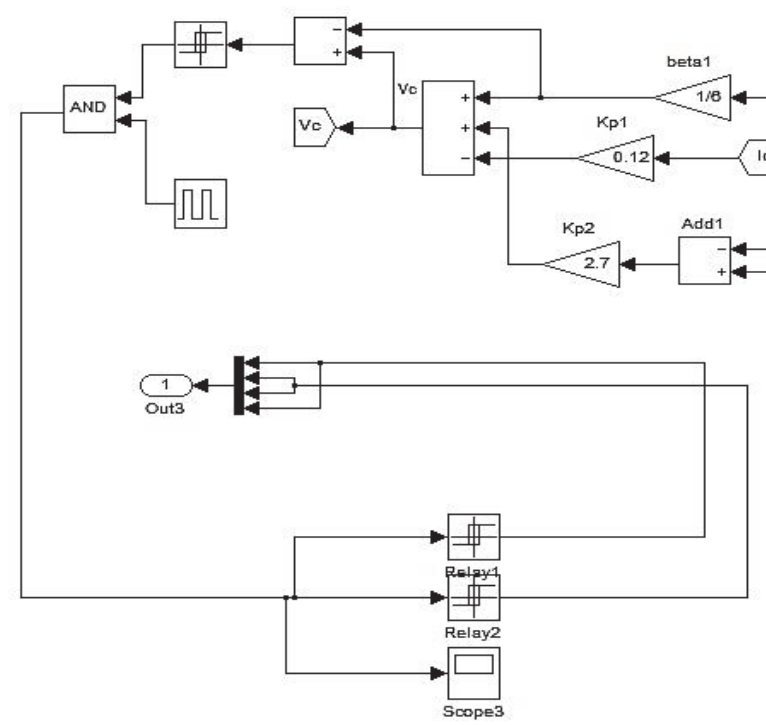

Fig.12. Simulation circuit for Sliding Mode Controller 


\section{RESULTS AND DISCUSSION}

The MATLAB software is used to simulate the proposed system to get results rapidly to the expectations and requirements. With fast simulation and easy user interface, MATLAB provides a powerful simulation .The detailed simulation diagram for the Sliding Mode Controller (SMC) with the super lift boost converter is shown in fig. 13 and its output current waveform is shown in fig. 14.
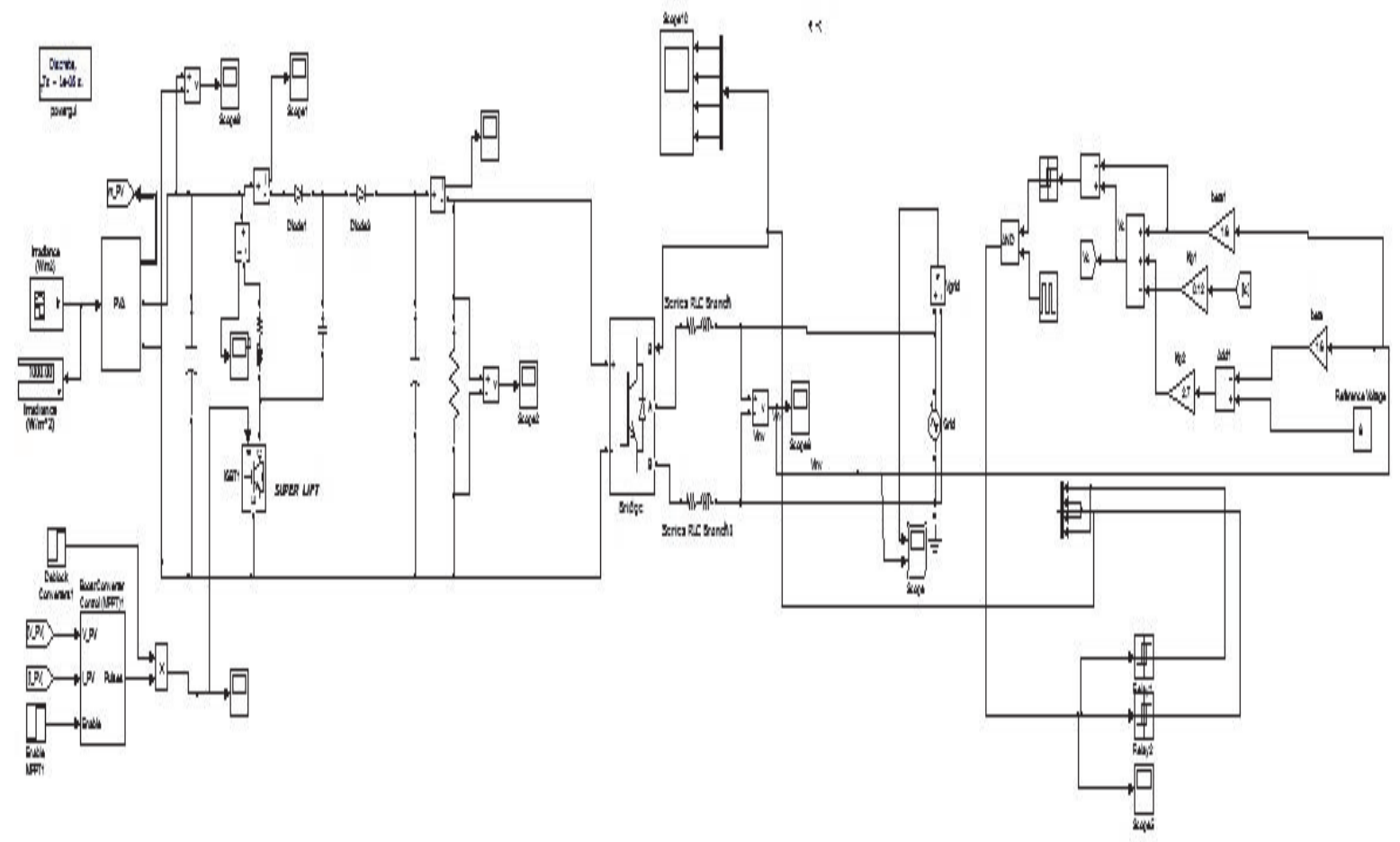

Fig.13. Simulation circuit for SMC based PVgrid integration

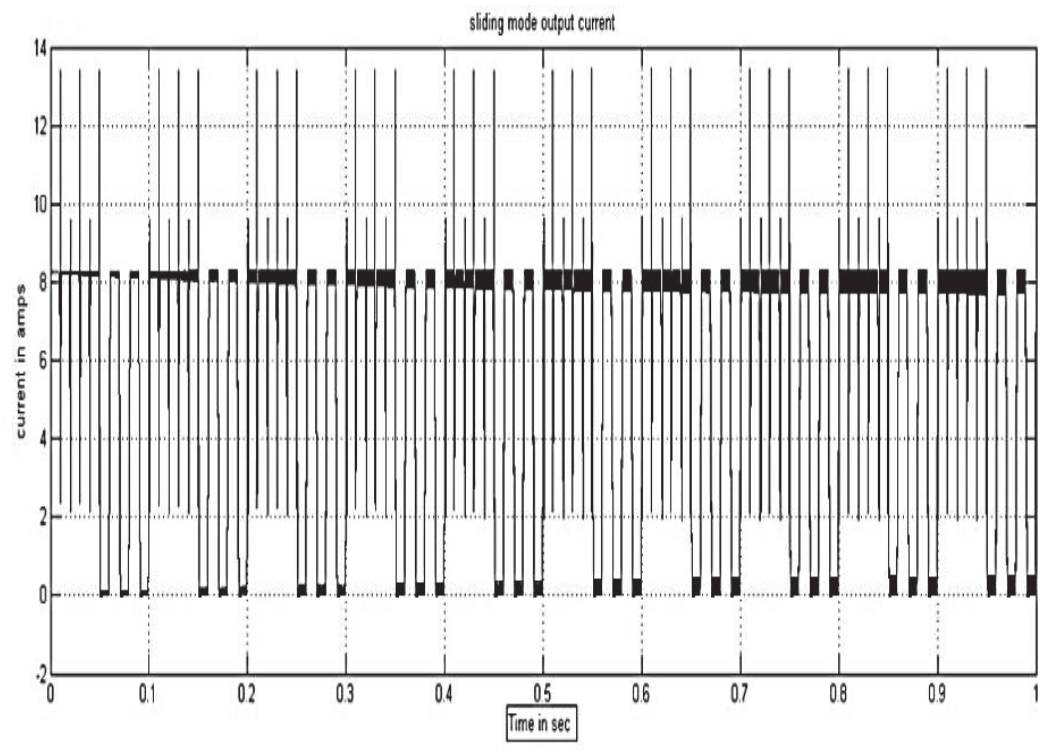

Fig.14. Output current by sliding mode 

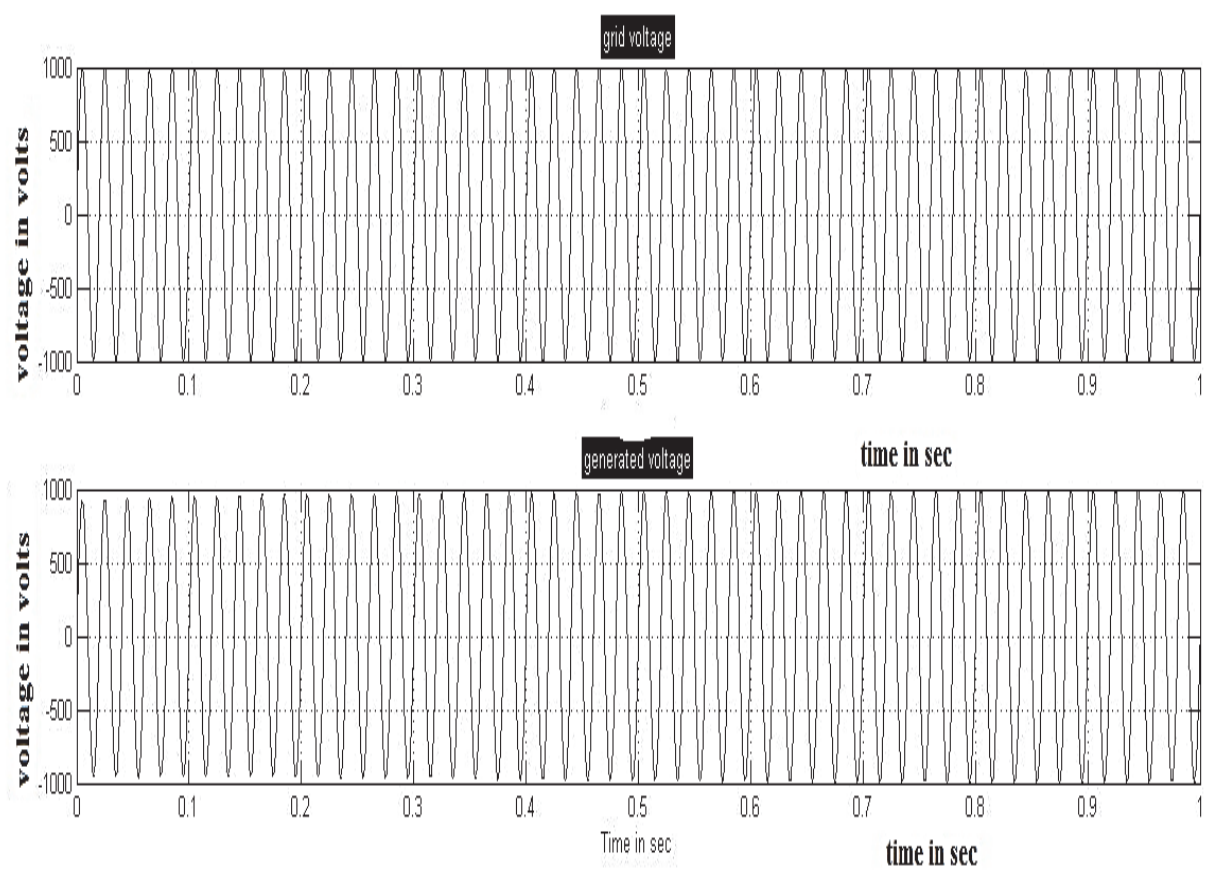

Fig.15.Synchronization waveform between grid and generated voltage

The generated voltage in SLBC with sliding mode controller (SMC) is synchronized with the supply voltage and it is shown in fig 15 . It is easy to understand that the produced voltage is synchronized with the grid voltage and it is tested with hardware implementation as a prototype and it is shown in fig16 and fig.17.

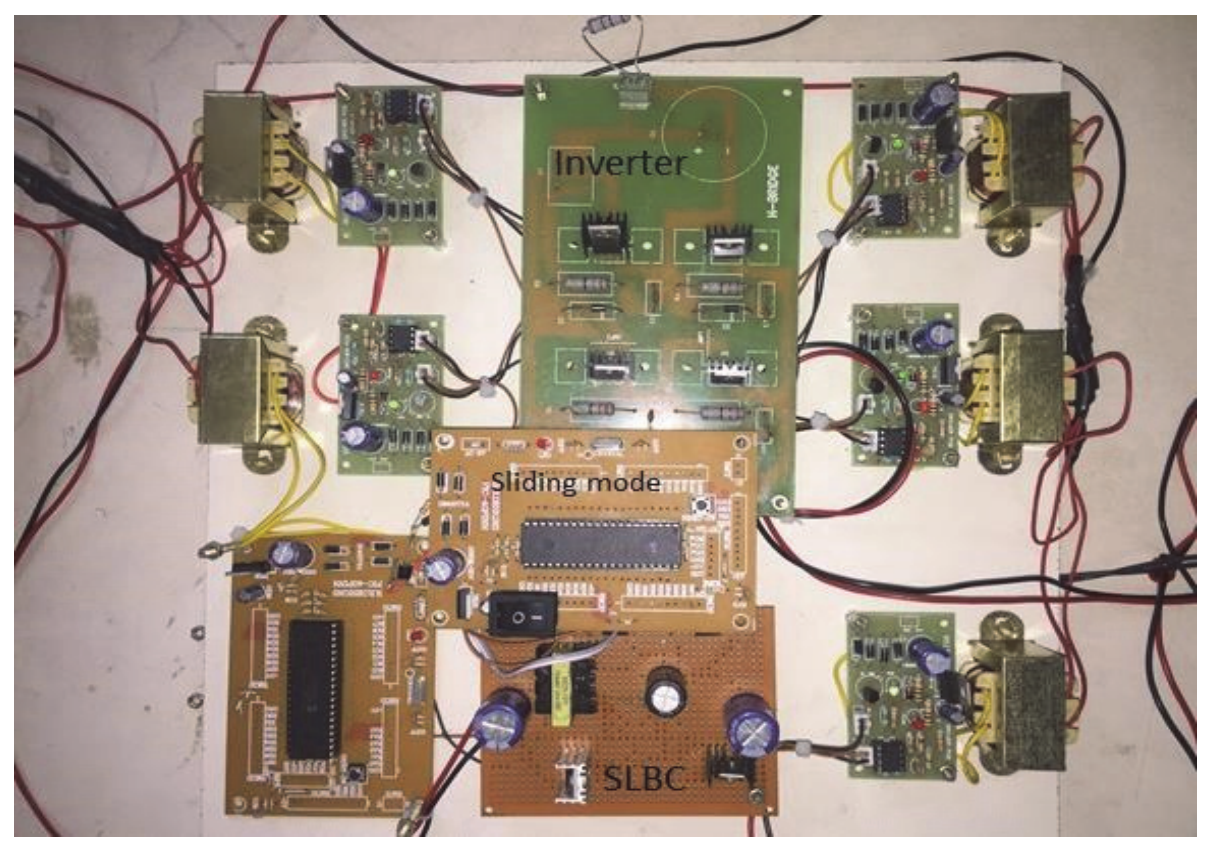

Fig. 16.Grid interconnected solar PV system usingSliding Mode Controller 


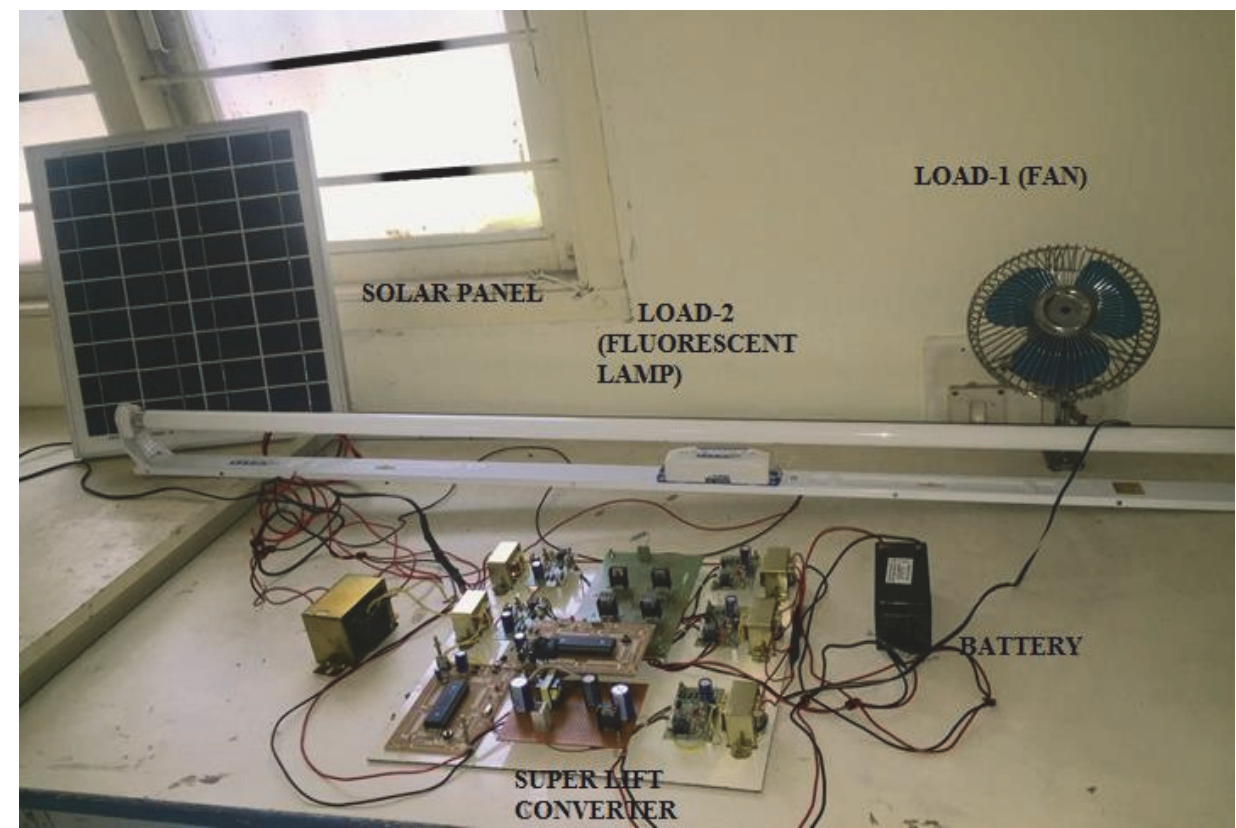

Fig. 17.Grid interconnected solar PV system with Load (Fluorescent lamp \& DC fan)

The output voltage obtained from the SLBC hardware is shown in fig.18.It is clear that, the obtained voltage from the Simulink model PV based SLBC is matched with the implemented prototype output.

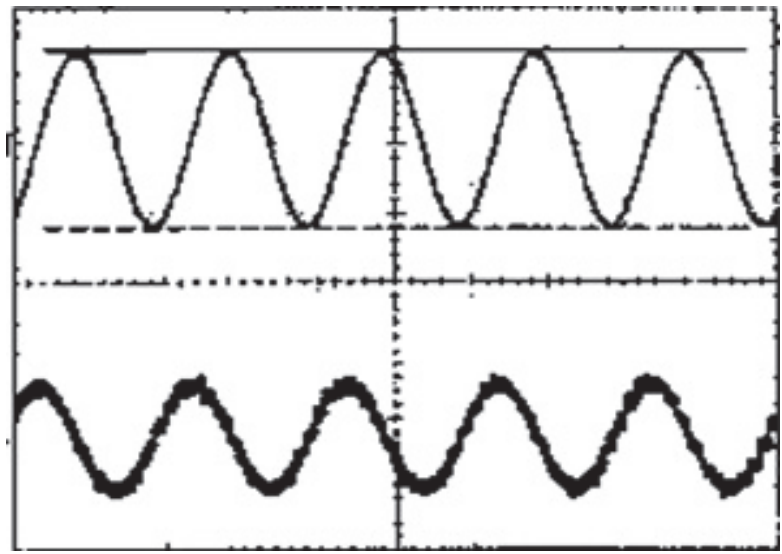

Fig. 18.Synchronization waveform in CRO display

\section{CONCLUSION}

The Sliding mode controller based Super lift boost Converter been proposed and modeledusingMatlabSimulink for the Fluorescent lamp \& DC fan.The results obtained has been verified with the implemented hardware using PIC Microcontroller.The proposed Incremental Conductance method in SLBC produces the sufficient grid voltage and it is integrated with the supply voltage fruitfully.

\section{REFERENCES}

[1] Praveenkumar chandran1 \&VishnukumarMurugesan"A solar power production system using MPPT with grid synchronization for distributed power production and distribution" vol. 4, issue 1, Feb 2014, 133-142.

[2] Priyanka R. Yelpale, dr. H. T. Jadhav, mrs. A. A.chandne, "control application of PV solar farm as STATCOM for increasing grid power transfer capacity" (issn no: 2454-7875), (NCMTEE-2k17) 27th march 2017.

[3] J. Sreedevi, Ashwin.N, M.NainiRaju Senior, "A Study on Grid Connected PV system”. ISSN: 2320-3331 Vol.02 Issue08 AJRN 06sep-2013

[4] GovindPoonia, SSPM Sharma B, “An Improved Grid Connected PV Generation Inverter Control System and Analysis of \%THD for Inverter”, ISSN: 2278-1676, Volume 9, Issue 4 Ver. VI (Jul - Aug. 2014).

[5] YaserAlhaddad, Adel Alsaad,"Grid-Connected Photovoltaic Power Systems: Domestic Simulation and Design in Kuwait (case study ofhe Public Authority Applied for Education and Training (PAAET))", e (IJES) Volume-5 Issue,ISSN (e): 2319 - 1813 ISSN (p): $2319-1805$.

[6] Maryam Shahjehan, WaleedShahjehan, Muhammad NaeemArbab, "Grid-Tied PV System with Energy Optimization", ISSN: 24092770, Vol. 4, Issue 10, PP. 184-189, October 2017.

[7] E. M. Natsheh, Member, IEEE, A. Albarbar, Member, IEE, and J. Yazdani, Member, IEEE, "Modeling and Control for Smart Grid Integration of Solar/Wind Energy Conversion System”. ISSN: 2320-3331 Vol.5 Issue 6,June2015 
[8] K PrasadaRao, DrSukhdeo Sao, Dr JBV Subrahmanyam, "Development of A Grid Connected Inverter for Solar PV Systems with Energy Capture Improvement Based On Current Control Strategy", IJSRP, Volume 3, Issue 4, April 2013 ISSN 2250-3153.

[9] DavudMostafaTobnaghi and Rahim vafaei, "The impacts of grid-connected photovoltaic system on distribution networks-a review",Vol.11,no.5,march2016 ISSN 1819-6608, ARPN Journal Of Engineering And Applied Sciences.

[10] SibasishPandaa, Anup Kumar Pandab and H.N Pratiharia, "Fault Analysis on Grid Connected MPPT based Photovoltaic System",01 August 2013, Vol.3, No.3 (August 2013), International Journal of Current Engineering and Technology ISSN 2277 - 4106.

[11] AbdulrahmanKalbat "PSCAD Simulation of Grid-Tied Photovoltaic Systems and Total Harmonic Distortion Analysis",. ISSN : 23200936 vol.6 Issue 8,Feb 2014

[12] Muhammad Waqas Khan, Muhammad Saleem,Ashfaq Ahmad and 4AhmadAyaz, "Synchronization of Photo-voltaic system with a Grid", IOSR Journal of Electrical and Electronics Engineering (IOSR-JEEE) e-ISSN: 2278-1676, Vol 7, Issue 4 (Sep. - Oct. 2013), PP 01-05.

[13] DhivyaBalakrishnan, DhamodharanShanmugam, K.Indiradevi, "Modified Multilevel Inverter Topology for Grid Connected Pv Systems", American Journal of Engineering Research (AJER) e-ISSN : 2320-0847 Volume-02, Issue-10, pp-378-384

[14] S. Dharanya, R. Baby, P. Alexraj, G. Balasubramanian "Design and Analysis of Super lift Boost Converter”.ISSN : 2320-0936 AJER

[15] V.K.Vishwhak "Design and Simulation of Superlift DC-DC Converter for Solar PV Applications"Volume 2, Issue 9, September 2017, pp. 22-28.

[16] Kjaer,SoerenBaekhoej,JohnK.Pedersen,andFredeBlaabjerg."Areviewof single-phase grid-connected inverters for photovoltaic modules."IEEETrans- actions on 41.5 (2005):1292-1306.

[17] AmakyeDickson,NMensahSitti,DanielOwusuDonkor,NinaPearlDoeand Ernest A. Amakye,"Grid Connected Inverters with unity Power Factor Re- newable Energy (PV) Application,’'International Journal of Innovative Sci- ENCE, Engineering \&Technology, Vol. 1 Issue 3, May2014.

[18] Kumaresh.V, MridulMalhotra, Ramakrishna N and SaravanaPrabu.R"Literature Review on Solar MPPT Systems” ISSN 2231-1297, Volume 4, Number 3 (2014), pp. 285-296

[19] V.K.Vishwhak, Dr.SeyezhaiRamalingam "Design and Simulation of Superlift DC-DC Converter for Solar PV Applications"Volume 2, Issue 9, September 2017, pp. 22-28

[20] M.Pradeep Chand, G.Ramesh "Design of new positive output super-lift luo converter for solar input in comparison with different DCDC converters" Volume: 03 Issue: 09-Sep -2016 p-ISSN: 2395-0072

[21] R. Suganya, K. Arulselvi , P. Pughazhendiran, S. Meenakshi "Photovoltaic Micro Inverter System Using Maximum Power Point Tracking"ISSN : 2248-9622, Vol. 3, Issue 5, Sep-Oct 2013, pp.787-792

[22] P.Pugazhendiran, U.Palani .S.KarthickP.Arulkumar, "Implementation of Novel Hybrid Wind Solar Energy Conversion System"ISSN: 2278 - 7798 Volume 2, Issue 5, May 2013

[23] P. Sanjeevikumar, P. Pugazhendiran and V. Rajeswari "Improvement of power system voltage stability using fuzzy based index" IEEE Trans- actions on 41.5 (2005):1292-1306.

[24] P.Pugazhendiran, Dr.J.Baskaran R.Vinothini,“A step-down and step-up DC-DC voltage converter combining KY and SR buck converters”ISSN:0976-1345 Vol5.No.2 2013

[25] Muhammad h. Rashid "Power Electronics Handbook" ppno:432-449 by Academic Press at 2001

[26] Nelson A. Patel, Jaydeep C. Baria “A Hysteresis Current Control Technique for Electronics Convertor”ISSN(Online): 2319-8753 Vol. 5, Issue 2, February 2016 